\title{
Typicality ratings for 893 exemplars of 93 categories
}

\author{
THOMAS M. GRUENENFELDER \\ Indiana University, Bloomington, Indiana
}

\begin{abstract}
Although the typicality effect has been much studied in the semantic memory literature, typicality ratings exist for exemplars from only a very limited number of categories. This lack of ratings frequently limits the range of stimuli that can be used in investigations of the typicality effect. As an aid in stimulus construction, this paper reports typicality ratings of 893 exemplars from 93 different categories.
\end{abstract}

Since the work of Collins and Quillian (1969), a variety of investigations have been directed at understanding the processes and structure of semantic memory (e.g., Collins \& Loftus, 1975; Lorch, 1981; McCloskey \& Glucksberg, 1979; Rips, Shoben, \& Smith, 1973; Roth \& Shoben, 1983). A task frequently used in these investigations is the category verification task. In this task, the subject is presented a sentence of the form "An $S$ is a P" ; "A robin is a bird" is an example. The subject is asked to determine as quickly as possible whether the sentence is true or false-that is, whether the concept named by the subject term of the sentence is a member of the category named by the predicate term. Usually, an individual is assumed to know the correct response; the dependent variable of interest is reaction time, the time from presentation of the stimulus to the subject's response.

One of the most robust findings to emerge from this research is the typicality effect. The typicality of an exemplar is the exemplar's rated goodness as a member of the category. People consistently rate some category members as better exemplars of that category than other category members (Rosch, 1975). For example, robins and sparrows are considered quite good exemplars of the category bird; eagles and hawks are somewhat less good exemplars, and chickens and penguins are worse. The typicality effect refers to the finding that the more typical an exemplar is of a category, the more quickly it is verified to be a member of that category (e.g., Rips et al., 1973; Rosch, 1975).

Investigations of the typicality effect have been hindered by the relatively small number of categories for which typicality ratings to exemplars have been obtained. Rosch (1975) obtained typicality ratings for exemplars of 10

This work was done as part of a dissertation submitted by the author to the Graduate Faculty of Indiana University in partial fulfillment of the requirements for the $\mathrm{PhD}$ degree. This research was supported in part by National Science Foundation Grant BNS 77-23863 to Frank Restle. Requests for reprints should be addressed to Thomas M. Gruenenfelder, AT\&T Bell Laboratories, Room 2B6, Crawfords Corner Road, Holmdel, NJ 07733 . categories. McCloskey and Glucksberg (1978) obtained typicality ratings for exemplars of 18 categories, 8 of which were also used by Rosch.

Investigators manipulating typicality have often relied on Battig and Montague's (1969) dominance norms. Dominance of an exemplar is defined as the number of subjects naming that exemplar as a member of the category within a given period of time. Battig and Montague collected dominance norms for 56 categories, including the categories for which typicality ratings had been obtained. These norms greatly increase the number of categories available to investigators manipulating typicality. However, although dominance and typicality ratings are well correlated (Mervis, Catlin, \& Rosch, 1976), the correlation is not perfect, and dominance norms are not typicality ratings. Dominance norms appear to be contaminated by word-frequency effects, but typicality ratings do not (Mervis et al., 1976). And, under some circumstances, even 56 categories are insufficient (e.g., Gruenenfelder, 1981).

This paper reports typicality ratings for 893 exemplars from 93 different categories. Ratings were not obtained for any of the categories used by McCloskey and Glucksberg (1978) or Rosch (1975), because of their availability. The purpose of reporting these ratings is to aid other investigators in stimulus construction when manipulating exemplar typicality.

\section{METHOD}

\section{Subjects}

A total of 50 paid Indiana University undergraduate subjects were recruited. The 34 female and 16 male subjects were all native speakers of English.

\section{Materials}

A total of 893 exemplars from 93 different categories were used. Some categories and exemplars were selected from the Battig and Montague (1969) norms. The remainder were generated by the author. The stimuli consisted of pairs of words, such as "house building," in which the first word named an exemplar and the second named a category of the exemplar. The ratings were originally used to generate stimuli for an experiment requiring one or two exemplars from each of many categories, rather than many exemplars from each of a few categories. Consequently, 
the number of exemplars for which ratings were obtained varied greatly from category to category and was small for some categories. Table 1 shows the category names and the number of exemplars used from each category.

\section{Design}

The categories were divided into two groups, one consisting of 445 exemplars from 46 categories and the other of 448 exemplars from 47 different categories. Thirty-one subjects rated exemplars from the first set of categories, and 27 from the second set. Eight of the subjects rated exemplars from both sets of categories in separate experimental sessions. This division of the categories into two sets kept the duration of the experimental session for a given subject to a reasonable length of time.

\section{Apparatus}

All instructions and stimuli were in uppercase black-on-white letters. These were presented on Miratel television monitors by ADDS 280
Matrix Raster Display units. The subjects responded by pressing one of six buttons arranged horizontally on a response box. The leftmost button was labeled "Very Typical" and the rightmost button "Very Atypical." All stimulus presentation, response recording, and event timing were controlled by a PDP-11/34 computer.

\section{Procedure}

Instructions were as follows:

This experiment is concerned with how people process the meaning of words. In particular, the experiment is concerned with pairs of words, such as "apple fruit," where the first word is a member of the category named by the second word. Generally, people think of some category members as being better examples of the category than others. For example, most people think that "apple" is a good example of "fruit," but that "raisin" is a much worse example, even though a raisin is a fruit. Good examples are called typical,

Table 1

Categories for Which Ratings were Obtained and Number of Exemplars Used from Each Category

\begin{tabular}{|c|c|c|c|}
\hline Category & Exemplars & Category & Exemplars \\
\hline Aircraft & 7 & Appliance & 15 \\
\hline Art & 7 & Asian & 7 \\
\hline Bedding & 6 & Beverage*. & 22 \\
\hline Body-Part* & 18 & Book & 5 \\
\hline Building & 11 & Building-Part* & 17 \\
\hline Candy & 6 & $\mathrm{Car}$ & 5 \\
\hline Carnivore & 16 & Ceremony & 6 \\
\hline City* & 10 & Cocktail* & 14 \\
\hline Container & 10 & Continent & 7 \\
\hline Cosmetic & 4 & Craftsman & 7 \\
\hline Crime* & 17 & Crop & 10 \\
\hline Currency* & 12 & Dairy-Product & 4 \\
\hline Disaster & 6 & Dog & 12 \\
\hline Drug & 12 & Dwelling* & 17 \\
\hline Emotion & 7 & Entertainer & 8 \\
\hline Entertainment & 7 & Exercise & 8 \\
\hline Explosive & 6 & Fabric* & 17 \\
\hline Farm-Implement & 6 & Fastener & 10 \\
\hline Flower* & 19 & Footwear* & 13 \\
\hline Foreigner & 9 & Fuel* & 13 \\
\hline Game & 9 & Garden-Tool & 6 \\
\hline Grain & 6 & Gun & 7 \\
\hline Herbivore & 11 & Jewelry & 7 \\
\hline Joint & 6 & Linen & 5 \\
\hline Livestock & 5 & Mammal & 13 \\
\hline Meat & 13 & Medical-Specialty & 6 \\
\hline Medicine & 7 & Metal* & 17 \\
\hline Minor & 6 & Music* & 16 \\
\hline Nobleman & 8 & Nut & 4 \\
\hline Occupation* & 25 & Office-Supply & 13 \\
\hline Officer* & 7 & Organ & 9 \\
\hline Percussion-Instrument & 4 & Pet & 6 \\
\hline Political-System & 8 & Politician* & 10 \\
\hline Poultry & 5 & Predator & 15 \\
\hline Prey & 17 & Primate & 7 \\
\hline Reading-Material* & 14 & Relative* & 14 \\
\hline Reptile & 6 & Rock & 5 \\
\hline Rodent & 7 & Room & 6 \\
\hline Science & 13 & Seafood & 12 \\
\hline Shellfish & 7 & Snack & 8 \\
\hline Snake* & 7 & Song & 3 \\
\hline Spice* & 17 & Storm & 4 \\
\hline String-Instrument & 7 & Sweetener & 4 \\
\hline Timepiece & 5 & Toiletry & 10 \\
\hline Tree* & 20 & Underwear & 7 \\
\hline Water-Body & 10 & Wind-Instrument & 9 \\
\hline Wood & 7 & & \\
\hline
\end{tabular}


and less good examples are called atypical. To continue the instructions, press any button on your response box.

In this experiment, your task is to judge how typical a category member is of its category. You will be shown pairs of words on your screen, one pair at a time. Your job is to judge how typical you believe the left-hand word of the pair to be of the category named by the right-hand word. If you think it is very typical of the category, press the left-most button on your response box-the one labeled "Very Typical." If you think it is very atypical, press the rightmost button-the one labeled "Very Atypical." Use the intermediate buttons for intermediate degrees of typicality. To continue the instructions, press any button.

After you make your response, the small white light above the button you pressed will be turned on for a short period of time. This is simply to indicate to you that your response was registered. The word pair will then be erased from the screen, and after another short period, the next pair will be presented. To continue the in structions, press any button.

There are no right or wrong answers in this task. Your judgment should be what you really believe. There is also no time pressure. You may take your time making each judgment. However, your first impression is usually best. To begin the experiment, press any button.

On each trial of the study, a single exemplar-category pair was rated. A trial was initiated by presentation of a word pair on a single line of the screen, centered horizontally and vertically. Once the subject had made a rating, a small white light was turned on above the button corresponding to the subject's response. After $500 \mathrm{msec}$, the light was turned off and the stimulus was erased from the screen. Presentation of the next stimulus began after a 1,500 -msec intertrial interval.

The order of stimulus presentation was random. In particular, stimuli were not blocked by category.

\section{RESULTS AND DISCUSSION}

The subjects' responses were scored by assigning a 1 to a response on the leftmost button, a 2 to a response on the button second from the left, and so on. Thus, the responses were treated as if they had been made on a 6-point rating scale, with a response of 1 indicating most typical and a 6 indicating most atypical. The mean response and its standard deviation across subjects were calculated for each exemplar. A table is available from the author showing these data for each exemplar of each category. (The typicality ratings are also included as an appendix in Gruenenfelder, 1981.) The table also shows the frequency of use of each exemplar, as measured by the Kučera and Francis (1967) norms. (Simple word frequency was used-words derived from the exemplar and words from which the exemplar was derived were not included in the calculation of word frequency.) Space considerations prevent presenting the entire table here. Table 2 shows, for illustrative purposes, a section of the complete table. This example covers two categories. Exemplars are organized within categories from most typical to least typical. The number in parentheses next to each category name is the number of subjects who rated exemplars from that category.

The mean ratings obtained for these stimuli cover a somewhat restricted range. In particular, very few stimuli were placed at the extreme end of "very atypical." Since an attempt was made to include a wide range of typicality in the stimuli, the reason for this restricted range is not clear. Nevertheless, stimuli based on the ratings presented here have resulted in strong and highly reliable typicality effects (Gruenenfelder, 1981).

Several correlations of the present data with other data were calculated. The first of these is the correlation of typicality ratings with frequency of use of the exemplar. Frequency of use was determined by the Kucera \& Francis (1967) norms. Because low ratings indicate highly

Table 2

Example From Larger Table Showing Mean Typicality Ratings, Their Standard Deviations, and Word Frequency of Exemplars (1 = Very Typical, 6 = Very Atypical $)$

\begin{tabular}{|c|c|c|c|c|}
\hline Category & Exemplar & Rating & SD & Frequency \\
\hline \multirow[t]{7}{*}{ Aircraft (31) } & plane & 1.03 & .18 & 114 \\
\hline & jet & 1.10 & .30 & 29 \\
\hline & helicopter & 1.81 & 1.33 & 1 \\
\hline & rocket & 2.35 & 1.66 & 7 \\
\hline & missile & 3.29 & 1.85 & 48 \\
\hline & blimp & 3.80 & 1.48 & 1 \\
\hline & balloon & 4.65 & 1.49 & 10 \\
\hline \multirow[t]{15}{*}{ Appliance (31) } & stove & 1.19 & .47 & 15 \\
\hline & washer & 1.23 & .54 & 2 \\
\hline & refrigerator & 1.26 & .57 & 23 \\
\hline & toaster & 1.26 & .57 & 0 \\
\hline & oven & 1.26 & .51 & 7 \\
\hline & mixer & 1.27 & .58 & 2 \\
\hline & dryer & 1.37 & .86 & 0 \\
\hline & can-opener & 1.55 & 1.01 & 0 \\
\hline & fan & 2.06 & 1.37 & 18 \\
\hline & bottle-opener & 2.10 & 1.49 & 0 \\
\hline & air-conditioner & 2.13 & 1.43 & 0 \\
\hline & radio & 2.58 & 1.64 & 120 \\
\hline & phonograph & 3.35 & 1.8 & 3 \\
\hline & stereo & 3.53 & 1.94 & 12 \\
\hline & telephone & 3.87 & 1.70 & 76 \\
\hline
\end{tabular}


Table 3

Simple and Partial Correlations Among Typicality, Frequency of Use, and Dominance

\begin{tabular}{lccc} 
& Typicality & Frequency & Dominance \\
\hline Typicality & & -0.19 & -0.56 \\
Frequency & -0.02 & & 0.36 \\
Dominance & -0.54 & 0.31 & \\
\hline
\end{tabular}

Note-Correlations above the diagonal are simple correlations; correlations below the diagonal are partial correlations with the third variable partialed out.

typical instances, a negative correlation would indicate that typical instances tend to be the more frequently used instances. The Pearson product-moment correlation of typicality with frequency of use was -.10 . Although statistically significant, this correlation, based on 893 pairs of observations, is of little practical significance. For these stimuli, frequency of use is not generally predictive of typicality.

Twenty-three of the categories, covering 349 exemplars, were identical to or synonymous with categories for which Battig and Montague (1969) collected dominance or production frequency norms. In Table 1, these categories are indicated by an asterisk. The data from these categories allow computation of several correlations of interest-between Kučera and Francis (1967) word frequency and typicality, between Battig and Montague dominance (defined as the number of subjects producing the exemplar as a category member in the Battig and Montague study) and typicality, and between word frequency and dominance. In addition, partial correlations between any two of these variables, partialing out the effect of the third, can be calculated. These correlations are presented in Table 3. Simple correlations are shown above the diagonal and partial correlations below the diagonal. In interpreting Table 3, because of the relatively large number of observations upon which each correlation is based, the relative magnitudes of the correlation are of more interest than their statistical significance. (With 349 observations, any correlation greater than .14 is significant, $\mathrm{p}<.01$.)
In general, the pattern of these correlations follows those reported by Mervis et al. (1976) for a different set of stimuli. Frequency of use and typicality are slightly correlated; the correlation disappears when the effect of dominance is partialed out. In contrast, dominance and typicality are more strongly correlated, and that correlation remains high when the effects of frequency of use are partialed out.

\section{REFERENCES}

Battig, W. F., \& Montague, W. E. (1969). Category norms for verbal items in 56 categories: A replication and extension of the Connecticut category norms. Journal of Experimental Psychology Monographs, 80(3, Pt. 2).

Collins, A. M., \& LofTus, E. F. (1975). A spreading-activation theory of semantic processing. Psychological Review, 82, 407-428.

Coluns, A. M., \& Quillian. M. R. (1969). Retrieval time from semantic memory. Journal of Verbal Learning and Verbal Behavior, 8 , 240-247.

GRUENENFELDER, T. M. (1981). Accessing semantic features and logical relations in category verification. Unpublished doctoral dissertation, Indiana University, Bloomington, IN.

KuČERA, H., \& Francrs, W. N. (1967). Computational analysis of present-day American English. Providence, RI: Brown University Press.

LORCH, R. F., JR. (1981) Effects of relation strength and semantic overlap on retrieval and comparison processes during sentence verification. Journal of Verbal Learning and Verbal Behavior, 20, 593-610.

MCCloskey, M., \& GluCKSBERG, S. (1979). Decision processes in verifying category membership statements: Implications for models of semantic memory. Cognitive Psychology, 11, 1-37.

MCCloskey, M. E., \& GluCKSBerg, S. (1978). Natural categories: Well-defined or fuzzy sets? Memory \& Cognition, 6, 462-472.

Mervis, C. B., CAtlin, J., \& Rosch, E. (1976). Relationships among goodness-of-example, category norms, and word frequency. Bulletin of the Psychonomic Society, 7, 283-284.

Rips, L. J., Shoben, E. J., \& Smith, E. E. (1973). Semantic distance and the verification of semantic relations. Journal of Verbal Learning and Verbal Behavior, 12, 1-20.

Rosch, E. (1975). Cognitive representations of semantic categories. Journal of Experimental Psychology: General, 104, 192-233.

Roth, E. M., \& Shoben, E. J. (1983). The effect of context on the structure of categories. Cognitive Psychology, 15, 346-378.

(Manuscript received March 1, 1984; revision accepted for publication July 20,1984 .) 